\title{
Milenarismo e política
}

\section{Renato Pinto Venâncio}

Romeiro, Adriana. Um visionário na corte de d. João $V$ : revolta e milenarismo nas Minas Gerais. Belo Horizonte: Editora UFMG, 2001. 286 páginas.

Na última década surgiram estudos inovadores a respeito da "cultura política” na sociedade colonial. Tal perspectiva consiste em procurar elaborar uma história política fora dos marcos das análises factuais e institucionais, quase sempre comprometidas com a reprodução $\mathrm{da}$ auto-imagem dos grupos dominantes. De acordo com a nova abordagem, o conteúdo tradicional cede lugar à investigação das representaçôes sociais e de suas conexóes com as práticas sociais, priorizando a problemática do simbólico. ${ }^{1} \mathrm{O}$ livro de Adriana Romeiro é um desses casos. A autora analisa o percurso de Pedro de Rates Henequim, português, que, como milhares de seus conterrâneos, tentou a sorte em Minas Gerais nas primeiras décadas do século XVIII. Retornando à terra natal, Hene- quim vê-se às voltas com graves acusações feitas pelo Santo Ofício, vindo a morrer em auto-de-fé de 1744 , sob a acusação de ser heresiarca.

Nesse processo inquisitorial, conforme sublinha Adriana Romeiro, revelam-se fascinantes interpretações dos textos bíblicos. O réu sustenta, entre outras convicçōes, a localização do paraíso em terras brasileiras. A autora, contudo, não encerra a pesquisa nessas constataçôes, mostrando a importância da análise crítica dos testemunhos inquisitoriais - como, aliás, de qualquer outra fonte histórica. Assim, sob o manto de heresiarca, esconde-se o Henequim conspirador político. O conventículo (para utlilizarmos um termo de época) do qual participa tem como projeto a passagem da América Portuguesa meridional, principalmente das cobiçadas regiôes mineradoras, para o domínio da Espanha ou então para o controle de d. Manuel, príncipe decaído da corte de d. João V. O acusado, apesar de ter prestado leais serviços à 
coroa, seja descobrindo lavras, seja combatendo o contrabando na região das minas, viu serem negados seus pedidos e reivindicações junto à burocracia metropolitana, sendo estes os possíveis motivos de sua atividade subversiva. Aliás, tendo em vista os fragmentados e incompletos testemunhos analisados, caberia considerar tais conspirações mais como "rumores" do que como conluios efetivos.

Ao contrário de outras investigações, em geral obcecadas pela relevância militar dos movimentos de revolta em Minas Gerais do século XVIII, a análise de Romeiro explora o universo cultural do conspirador, sublinhando sua possível manipulação. Descarta, no entanto, a interpretação de que o processo fosse, do começo ao fim, uma farsa (p. 68). A autora atinge, nesse momento, como ela própria observa, o âmago da questão. Explorando o discurso de Henequim do ponto de vista de suas articulações internas, seja em seus vínculos com a teologia, seja em seu ideário político, Adriana Romeiro associa o conteúdo do depoimento do suposto heresiarca a tradições intelectuais bastante antigas. A primeira delas diz respeito à vertente judaica, descrita no Antigo Testa- mento, principalmente no Livro de Daniel. A segunda deita raízes em Portugal, estando presente na poesia de Bandarra, do início do século XVI, e nos escritos de Antonio Vieira, de fins do século XVII, através de referências ao Quinto Império. Há também, no referido depoimento, traços de sebastianismo, crença que, a partir da perda da independência de Portugal frente à Espanha, conquistou aliados entre letrados ${ }^{2}$ e teve importante papel no movimento de restauração de 1640 .

Nesse cadinho cultural, composto por várias linhagens intelectuais, Henequim construiu sua peculiar cosmologia milenarista. Passo a passo, Adriana Romeiro desven$\mathrm{da}$ as relações entre certos aspectos do universo cultural da época e o conjunto de crenças do acusado de heresia. Tal análise é um exemplo fascinante de interpretação da religiosidade não como irracionalismo ou expressão de uma falsa consciência, mas sim como uma visão de mundo, uma ferramenta cognitiva de organização e interpretação da realidade, com profundas conseqüências políticas. Assim, nas páginas $166-167$, lemos que as teses profético-milenaristas em nada eram inocentes. Um exemplo disso esta- 
ria no fato de que, ao fazer da Colônia o local do paraíso, sede do Quinto Império, o discurso milenarista subvertia politicamente a relação centro-periferia pela qual a metrópole-colônia deveria se pautar. $\mathrm{O}$ universo mental subjacente à malograda conspiração também lança uma pá de cal (mais uma!) sobre as interpretações que concebem os movimentos políticos do período colonial em função de um suposto ideal de libertação nacional (p. 210); crítica há muito repetida, mas nem sempre acompanhada de interpretações alternativas sobre o ideário que orientava essas mesmas revoltas. Mais ain$\mathrm{da}$, a autora brinda o leitor com interessantes sugestôes de pesquisa. Uma delas diz respeito à origem dos índios. No depoimento é registrado o debate, que envolveu vários rabinos e padres, sobre a origem judaica dos povos indígenas, uma das tribos expulsas da Babilônia (p.114); afirmação que sugere uma matriz religiosa $^{3}$ para algumas idéias caras ao indianismo do século XIX, como, por exemplo, a noção de que os índios descendiam de populações mediterrâneas. Outra sugestão de pesquisa diz respeito à circulação, em Minas Gerais do início do século XVIII, de obras proibidas na forma de manuscritos - no caso específico, a Clavis Prophetarum, de Antonio Vieira (p. 152). Embora se trate de um único caso até agora registrado, esse fato sugere que tão importante quanto a investigação da circulação de livros é a pesquisa que incida sobre a produção e a circulação do papel no mundo colonial, base para a divulgação de textos não controlados pelo poder metropolitano. Last but not least, Romeiro identifica a permanência de tensões entre paulistas e reinóis, mesmo após o fim do que se costumou definir como Guerra dos Emboabas (1707-1709), sugerindo uma instigante interpretação a respeito da Revolta de 1720 (p. 199).

Como pode ser percebido, a obra em questão apresenta um conjunto de contribuiçõoes substanciais. No entanto, cabe registrar algumas ressalvas. A autora insiste em afirmar que a ação contra Henequim encobria uma perseguição política, enfatizando a despolitização sofrida pelo libelo inquisitorial, no qual o réu deixa de ser associado a uma conspiração malograda para encarnar o estereótipo de heresiarca (p. 40). Conforme é sugerido, o texto do processo estava subordinado à retórica teológica do Santo Ofício. No entan- 
to, outras pistas poderiam ser exploradas. Uma delas seria a de abordar comparativamente a atividade do conspirador com a de outros revoltosos perseguidos pela Inquisição. Este, por exemplo, foi o caso de Manoel Beckman, líder da revolta ocorrida no Maranhão entre 1684 e 1685, cujas investigaçôes que a Inquisição mandou fazer ... confirmam quanto a politica e a religião estavam interligadas.... [e quanto] heresia religiosa e heresia politica caminhavam juntas. ${ }^{4}$ Em outras palavras, quando visto em uma perspectiva comparada, é possível suspeitar do caráter excepcional não do conteúdo do processo de Henequim, mas sim dos quadros institucionais que lhe deram origem.

Ao se concentrar, aliás com muito brilho e talento, sobre a matriz letrada das idéias e projetos do suposto heresiarca, Romeiro acaba abordando apenas tangencialmente a temática do milenarismo popular. Da mesma forma que no caso anterior, a autora priva-se de investigações que a auxiliariam a melhor compreender o alcance das idéias de Henequim. Assim, cabe lembrar que, há alguns anos, Alida Metcalf tem procurado estabelecer as relaçóes entre o movimento quilombola e a tradição milenarista seiscentista. ${ }^{5}$ Antes dela, Liana Maria S. Trindade propôs interpretar o processo de desagregação do sistema escravista a partir de signos escatológicos de um tempo apocalíptico, observando que surgiam, entre os escravos, profetas com mensagens de redenção, santos curandeiros que aglutina[vam] $e$ expressa[vam] as esperanças populares, como os redentores de um mundo em extinção. ${ }^{6}$ Luiz Mott — aliás em livro citado por Adriana Romeiro também investigou esse milenarismo popular, traçando o perfil de uma ex-escrava que previa um novo dilúvio e o retorno de d. Sebastião; essa última convicção, de forte penetração popular, foi fartamente registrada entre numerosos viajantes, como Spix e Martius, Lucock, Ferdinand Denis ou Charles Expilly. ${ }^{7}$ Por mais polêmicas que sejam algumas destas interpretações, elas mostram que as crenças milenaristas eram compartilhadas entre os segmentos mais pobres - e mais numerosos — da antiga sociedade brasileira, daí provavelmente derivando, para a coroa portuguesa, o caráter político ameaçador do discurso de Henequim.

Enfim, o livro Um visionário na corte de d. João V sugere novos caminhos para se pensar a "política" e a 
"revolta" no período colonial. Ele não só contribui para uma melhor compreensão do passado, como também instiga-nos a refletir sobre o presente. Quando, nos dias atuais, assistimos ao ressurgimento do fundamentalismo (milenarismo?!) religioso em escala planetária, livros como o de Adriana Romeiro lembram-nos a importância do mito e da religião como elementos formadores de opiniōes políticas, sugerindo assim que nosso futuro pode estar no passado.

\section{Notas}

${ }^{1}$ FALCON, Francisco. História e poder. CARDOSO, Ciro Flamarion e VAINFAS, Ronaldo (orgs.). Dominios da História: ensaios de teoria e metodologia. Rio de Janeiro: Campus, 1997, p. 76.

${ }^{2}$ HERMANN, Jacqueline. No reino do desejado: a construção do sebastianismo em Portugal nos séculos XVI e XVII. São Paulo: Companhia das letras, 1998, p. 247.

${ }^{3}$ Em outro texto, a autora afirma que "a reflexão sobre a ascendência das populações indígenas ocupa um lugar central nas especulaçōes profético-messiânicas". ROMEIRO, Adriana e RAMINELLI, Ronald. São Tomé nas Minas: a trajetória de um mito no século XVIII. Vária História, 21, p. 67, 1999.

${ }^{4}$ LIBERMAN, Maria. O levante do Maranhão: "Judeu Cabeça do Motim", Manoel Beckman. São Paulo: Centro de Estudos Judaicos FFLCH/USP, 1983, p. 6.

${ }^{5}$ METCALF, Alida C. Os limites da troca cultural: o culto da Santidade no Brasil colonial. SILVA, Maria Beatriz Nizza da. Cultura portuguesa na Terra de Santa Cruz. Lisboa: Estampa, 1995, pp. 35-52; Millenarian slaves? The santidade de Jaguaripe and slave resistance in the Americas. The American Historical Review, v. 104, n. 5, pp. 15311559, 1999; Messianismo e resistência à escravidão no Brasil seiscentista. SILVA, Maria Beatriz Nizza da. Brasil: colonização e escravidão. Rio de Janeiro: Nova Fronteira, 2000, pp 311-323.

${ }^{6}$ TRINDADE, Liana Maria Salvia. A crise do sistema escravocrata e as interpretações míticas da realidade social. Revista do Instituto de Estudos Brasileiros, v. 30, p. 68, 1989. ${ }^{7}$ MOTT, Luiz. Rosa Egipcíaca: uma santa africana no Brasil. São Paulo: Bertrand Brasil, 1993, p. 569. 